\title{
Material Educativo e seu público: um panorama a partir da literatura sobre o tema
}

\section{Educational Material and its public: an overview from literature on the matter}

\author{
1 Ana Paula Rodriges Cavalcante de Paiva anaprcp31@gmail.com \\ 2 Eliane Portes Vargas epvargas@ioc.fiocruz.br
}

\section{RESUMO}

A produção de materiais educativos tem sido considerada pertinente em abordagens relacionadas a várias temáticas do ensino, em ciências e/ou em saúde e ambiente, sobretudo quanto aos aspectos relacionados às etapas de seu desenvolvimento e o processo participativo que as caracterizam. Neste trabalho, procurou-se apresentar algumas reflexões sobre o que tem sido produzido de conhecimento acerca dos materiais educativos, visando uma maior compreensão das análises presentes na literatura nacional sobre o tema. Para tanto, foi realizado um levantamento de artigos na Base Scielo-Brasil buscando identificar nos mesmos aspectos relacionados à produção, público, uso e avaliações de materiais educativos. Na caracterização conjunta dos 19 artigos levantados, apontam-se as diversidades de materiais analisados, as predominâncias da temática da saúde e da análise realizada pelos autores ou pelo público, que serão discutidas no presente trabalho.

Palavras-chave: Materiais educativos e de divulgação. Promoção da saúde. Participação comunitária. Literatura de revisão como assunto. Público.

\begin{abstract}
The production of educational materials has been considered relevant in approaches related to various issues of teaching, sciences and/or health and environment, especially in matters related to the stages of their development regarding the participatory process that characterizes them. In this work, we tried to present some reflections on what knowledge has been produced about educational materials, reaching a greater understanding of the sort of analyzes favored in national literature on the subject. For this, a survey of articles in Scielo-Brazil Base was conducted, seeking to identify their related production approach, public use and evaluations of educational materials. The joint characterization of 19 articles points to the diversity of analyzed materials, predominance of health subject,-analysis conducted by the authors and public, which will be discussed in this work.
\end{abstract}

Keywords: educational and promotional materials; health promotion; consumer participation; review literature as topic; public.

\footnotetext{
1 Mestranda do Programa em Ensino em Biociências e Saúde/IOC/Fiocruz e Tecnologista em Saúde Pública do Campus Fiocruz Mata Atlântica/ CFMA/Fiocruz.

2 Pesquisadora do Instituto Oswaldo Cruz/IOC/Fiocruz e Docente do Programa em Ensino em Biociências e Saúde/IOC/Fiocruz
} 


\section{INTRODUÇÃO}

A importância dos materiais educativos nos processos de ensino-aprendizado e de promoção da saúde tem sido discutida em diversos trabalhos em variadas dimensões relacionadas a: tecnologias educacionais e suas interfaces com a educação, comunicação e saúde (MONTEIRO, et al, 2006); transdiciplinariedade da área de saúde, ciências sociais e artes, aplicando imagens para o desenvolvimento e avaliação de materiais educativos na saúde (PIMENTA et al, 2006); apectos cognitivos e lúdicos dos jogos educativos, por exemplo, como estratégia para o ensino e aprendizagem de conceitos (ZANON et al, 2008); necessidade de avaliação e de estudos de recepção para que sua produção seja associada ao contexto do público ao qual se destina (NOGUEIRA et al, 2009); devido o seu disseminado uso na prática educativa, os materiais devem valorizar os conhecimentos e experiências do sujeito receptor (FREITAS; REZENDE FILHO, 2011).

O material educativo pode ser compreendido como um facilitador da experiência de aprendizado ou mediada para o aprendizado, de modo a não ser considerado apenas um objeto que proporciona informação, mas num dado contexto, facilitador ou apoio para o desenvolvimento de uma experiência de aprendizado envolvendo mudança e enriquecimento em algum sentido, seja conceitual, perceptivo, axiológico ou afetivo, de habilidades ou de atitudes (KAPLÚN, 2003).

Contudo, é preciso olhar também para o público ao qual se destina o material, tendo a clareza de que os indivíduos farão suas leituras e análises de forma individual ou em grupo e poderão tomar suas decisões baseadas em diversos outros fatores e não apenas na informação recebida pelo material educativo. Sendo assim, as informações dos materiais educativos deveriam ser planejadas considerando a possibilidade de ocorrer um processo de tomada de decisão pelo leitor, ao invés de o persuadir para uma mudança de comportamento ou atitude (ARAÚJO, 2006). Talvez, para que este olhar ocorra, seja necessário refletir um pouco sobre a natureza deste público, passando a enxergá-lo sob o prisma da concepção histórico-cultural, onde "O homem é um ser social, constituído fundamentalmente por meio das e nas relações sociais em condições históricas e culturais da vida concretamente vivida.” (BRITO, 2005, p. 10).

Outrossim, seja necessário se desvencilhar do modelo mecanicista que compreende o homem como uma máquina, bem como do determinismo biológico que o explica por suas funções adaptativas. Para tal, consideramos a pertinência de assinalar as complexas relações entre esta problemática, a que envolve a natureza do público para o qual são destinados os materiais, e os modos de caracterizá-lo e descrevê-lo no plano das ações educativas. Como já indicado na literatura sobre o tema (Monteiro; Vargas, 2006), o termo ‘público-alvo’ é uma categoria comumente utilizada no desenvolvimento de materiais. No entanto, mostra-se limitada como categoria analítica e explicativa no que concerne à classificação dos materiais tendo em vista a concepção mecanicista da qual decorre. Isto porque ao exprimir de modo abrangente e genérico os públicos aos quais as ações se destinam, limita a compreensão e a descrição dos sujeitos, uma categoria complexa, e de seu grupo de pertencimento cultural em termos das lógicas que os norteia em suas decisões na tessitura das intervenções no âmbito da educação e do ensino. Nesse sentido, o pesquisador González Rey (2003), pode nos ajudar na mudança deste paradigma ao reconverter nosso olhar para o caráter social do homem, não determinado externamente exclusivamente e sim atuando a partir de sua condição subjetiva quando está comprometido numa dada ação social.

(...) o social atua como elemento produtor de sentido partindo do lugar de sujeito em seu sistema de relações e da história desse próprio sujeito, que também não representa uma estrutura interna passiva, definitiva de seus comportamentos atuais, e sim uma configuração geradora de sentidos que não podem isolar-se dos sentidos produzidos no curso da experiência do sujeito. (GONZÁLEZ REY, 2003, p.224).

Este autor discute e analisa duas categorias em sua obra: sujeito e subjetividade, sendo a primeira, para fins do presente trabalho, relevante para construir, compreender e valorizar esse ser, homem, sujeito, leitor que faz suas próprias escolhas. González Rey (2003), faz um resgate da ideia do sujeito com capacidade de opção, 
de ruptura e de ação criativa, diferentemente da ideia de controlador do mundo ao seu redor. Esta ideia de sujeito resgata também os caráteres dialético e complexo do homem, que simultaneamente representa um ser singular e social. Porém esta relação não se dá como uma determinação externa, trata-se de uma relação recursiva em que cada indivíduo está implicado na configuração onde se manifesta a ação do outro. Assim, o conceito de sujeito é incompatível com o determinismo mecanicista causalista, pois a ação do sujeito é imprevisível. De forma simplificada, a categoria sujeito pode ser definida como indivíduo consciente, intencional, atual, interativo e emocional, ou seja, um sujeito que se expressa pelos processos de pensamento e linguagem, processos nos quais está comprometido nas suas relações com os outros num dado espaço social, atuando e se expressando a partir do estado emocional de quem fala e pensa.

A produção de materiais educativos tem sido considerada pertinente em relação a várias temáticas do ensino, seja em ciências ou em saúde e ambiente, sobretudo quanto aos aspectos relacionados às etapas de seu desenvolvimento; nela tem sido apontada a necessidade de estudos que reúnam um maior conhecimento sobre suas apropriações e uso pelo público alvo.

O presente trabalho ${ }^{3}$ faz parte de um estudo em andamento no Programa de Pós Graduação-Ensino em Biociências e Saúde do IOC/Fiocruz que visa analisar o uso, por seu público, do material educativo denominado Caderno de Práticas e Soluções (CPS). O material foi produzido coletivamente por um grupo de pesquisadores do Campus Fiocruz Mata Atlântica (CFMA) e externos ao Campus, lideranças comunitárias do entorno e moradores da antiga Colônia Juliano Moreira, em Jacarepaguá/RJ. O estudo tem por pressuposto haver maior possibilidade de adesão dos indivíduos aos materiais e ferramentas educativas a eles dirigidos quando seu desenvolvimento resulta em produções que incorporam a visão do público ao qual se destina. Este é o caso do CPS, uma Tecnologia Social por definição cujos pilares são a participação, transformação e reaplicabilidade (CCSP, 2014), que valorizou desde o início o diálogo entre diferentes atores envolvidos, especialmente na sua concepção, considerando-os sujeitos ativos no processo de construção deste material.

Visando o delineamento da pesquisa, um passo importante foi o levantamento da literatura que versa sobre o tema para substanciar os argumentos que a sustentam. Em Monteiro e Vargas (2006), fica clara a importância, para a área da saúde coletiva, de se refletir sobre as repercussões do uso dos materiais junto à população-alvo da ação, podendo trazer novas perspectivas. Igualmente, na área de ensino de ciências, poderia somar para uma maior reflexão sobre a prática acerca do desenvolvimento de materiais, especialmente no que se refere ao retorno (feedback) do público ao qual se destinam, sobretudo visando assegurar que os esforços empenhados, no caso específico do CPS (CFMA), sejam realmente de interesse do público, garantindo a efetividade dos materiais que são produzidos. Torna-se, portanto, um desafio decidir como melhor alcançar o público tendo em vista que ele recebe diversos tipos de informações por diversas mídias (FIELD; POWELL, 2001). Estes autores também consideram que o desafio da "área” de "public understanding of science" - compreensão pública da ciência, é conceber e implementar métodos eficientes de explicar a investigação em curso para o leigo de modo a atrair, prender sua atenção e encontrar canais de comunicação, que sejam de fácil acesso para este público.

Diante dessa perspectiva, procurou-se, em um primeira etapa, pesquisar o que tem sido produzido de conhecimento e análises/avaliações sobre materiais educativos. Ressalta-se que foram considerados os diversos tipos de materiais com seus variados suportes, como os jogos e os materiais de divulgação: cartazes, cartilhas, folders, panfletos, livretos. Estes materiais de divulgação são também considerados educativos, pois fazem parte da mediação entre os profissionais de saúde e a população no espaço dos serviços de saúde (MONTEIRO; VARGAS, 2006).

3 Este trabalho consiste em uma versão ampliada da comunicação oral apresentada no X Encontro Nacional de Pesquisa em Educação em Ciências - X ENPEC -Águas de Lindóia, SP - 24 a 27 de Novembro de 2015, intitulado:

Os Materiais Educativos e seus públicos: um panorama a partir da literatura sobre o tema. Para versão atual foi realizada nova busca considerando os mesmos descritores e incluindo os anos 2014-2015, com o intuito de atualizar o panorama e ampliar análises produzidas sobre o tema. 
Neste artigo, apresentamos o panorama resultante da investigação que buscou compreender a natureza das pesquisas nacionais realizadas com os materiais educativos e seus públicos. Este objetivo foi alcançado pelo levantamento bibliográfico na base eletrônica Scielo-Brasil (Scientific Electronic Library Online), portal de revistas nacionais que organiza e publica textos completos. Para definir quais artigos comporiam este panorama, assumiu-se como critério seletivo que os mesmos deveriam contribuir para responder aos seguintes questionamentos: Quais tipos de materiais têm sido analisados? Quais temáticas estes materiais abordam? Eles foram produzidos para qual público? Qual o contexto de uso destes materiais? Sob que aspectos metodológicos as análises foram realizadas? As análises foram realizadas por quais sujeitos?

\section{METODOLOGIA: LEVANTAMENTO E CARACTERIZAÇÃO DE ARTIGOS NACIONAIS}

O panorama proposto assemelha-se ao percurso percorrido em uma revisão de literatura devido seu caráter inventariante e descritivo (FERREIRA, 2002). Para Creswell (2007), a literatura revisada é útil para situar o problema a ser pesquisado na introdução de um dado estudo e existem diversas formas de fazer, mas a sistemática para apreender, avaliar e resumir a literatura é a mais utilizada pelos acadêmicos e foi empregada neste estudo. Nesta direção, na metodologia adotada, o levantamento e a caracterização dos artigos foram orientados de acordo com os procedimentos descritos por Creswell (2007), de modo a responder os questionamentos apresentados na seção anterior. A escolha da base SciELO-Brasil deu-se com vistas a obter um panorama do conjunto de artigos publicados sobre a temática no território nacional. O levantamento e a classificação foram desenvolvidos nas três fases descritas a seguir:

1- Definição dos descritores - Foram realizadas buscas sucessivas com os descritores 'materiais', 'educativos' e 'didáticos' aplicados ao campo 'Todos os índices', visando ampliar a identificação dos artigos relacionados às perguntas do estudo. Com o descritor 'materiais' foram obtidos 5.537 resultados, que combinados à palavra 'educativo' foram reduzidos a 34. Uma nova busca usou as palavras 'materiais' e ‘didáticos' resultando em 54 artigos, que correspondem ao número final de artigos analisados. $\mathrm{O}$ ano das publicações não foi delimitado na busca.

2- Seleção dos artigos - Procedeu-se a uma leitura de todos os títulos e resumos dos 54 artigos identificados, dentre os quais alguns apresentaram dúvida quanto à sua pertinência em relação ao objeto do estudo, sendo necessária uma leitura complementar dos objetivos e/ou do artigo completo para proceder à sua inclusão no corpus analisado. Com base nas questões apresentadas anteriormente, foram selecionados para a classificação e nova análise 19 artigos, sendo excluídos os de relato de experiência e artigos de revisão (CRESWELL, 2007).

3- Classificação - Os 19 artigos selecionados foram lidos na íntegra e, a partir deste procedimento, foi realizada uma espécie de ficha catalográfica por unidade, contendo as seguintes características: Título, Autores, Problema de Pesquisa, Objetivos, Referenciais Teóricos, Metodologia e Conclusão. Muitos destes artigos não apresentaram explicitamente estas indicações, mas este percurso tentativo e sistemático de classificação permitiu a identificação dos caminhos percorridos nas pesquisas e a extração do maior número possível de informações para a classificação dos artigos apresentados no Quadro 1 da página seguinte. 
Quadro 1: Caracterização dos Artigos Analisados levantados na base Scielo (2003 - 2015)

\begin{tabular}{|c|c|c|c|c|c|c|}
\hline $\begin{array}{l}\text { Autores } \\
\text { dosArtigos }\end{array}$ & \begin{tabular}{|l|} 
Tipos de \\
Materiais \\
Analisados \\
\end{tabular} & $\begin{array}{l}\text { Área } \\
\text { Temática }\end{array}$ & Público & $\begin{array}{l}\text { Locais/Formas de } \\
\text { Uso }\end{array}$ & \begin{tabular}{l|} 
Aspectos \\
Metodológicos \\
da Análise \\
\end{tabular} & $\begin{array}{l}\text { Sujeitos da } \\
\text { Análise }\end{array}$ \\
\hline LUZ et al, 2003 & Diversos & Leishmania & Pacientes & Serviços de Saúde & $\begin{array}{l}\text { Qualidade da } \\
\text { informação dos } \\
\text { materiais }\end{array}$ & Especialistas \\
\hline $\begin{array}{l}\text { KELLY- } \\
\text { SANTOS e } \\
\text { ROZEMBERG, } \\
2005 \\
\end{array}$ & Impressos & $\begin{array}{l}\text { Saúde do } \\
\text { trabalhador }\end{array}$ & Trabalhadores & Distribuição & $\begin{array}{l}\text { Processos } \\
\text { Comunicativos }\end{array}$ & Autores Artigo \\
\hline LUZ et al, 2005 & Folheto & Leishmania & $\begin{array}{l}\text { Profissionaisde } \\
\text { Saúde e Leigos }\end{array}$ & Educação em Saúde & $\begin{array}{l}\text { Potencial } \\
\text { Informativo }\end{array}$ & $\begin{array}{l}\text { Prof. de Saúde } \\
\text { e Leigos }\end{array}$ \\
\hline CASTRO, 2007 & $\begin{array}{l}\text { Materiais } \\
\text { Educativos }\end{array}$ & $\begin{array}{l}\text { Alimentação } \\
\text { Saudável }\end{array}$ & $\begin{array}{l}\text { Adolescente } \\
\text { Merendeiras } \\
\text { Professores } \\
\text { Prof. Saúde }\end{array}$ & Educação em Saúde & $\begin{array}{l}\text { Opinião, } \\
\text { Leitura e } \\
\text { Aplicação }\end{array}$ & $\begin{array}{l}\text { Adolescentes } \\
\text { Merendeiras } \\
\text { Professor } \\
\text { Prof. Saúde }\end{array}$ \\
\hline $\begin{array}{l}\text { FREITAS e } \\
\text { CABRAL, } 2008\end{array}$ & $\begin{array}{l}\text { Folheto } \\
\text { Educativo }\end{array}$ & Traqueostomia & $\begin{array}{l}\text { Pacientes } \\
\text { Traqueostomiza- } \\
\text { dos }\end{array}$ & Educação em Saúde & $\begin{array}{l}\text { An. Sintática, } \\
\text { Lógica e } \\
\text { Linguagem }\end{array}$ & $\begin{array}{l}\text { Autores do } \\
\text { Artigo }\end{array}$ \\
\hline $\begin{array}{l}\text { PIMENTA et al, } \\
2008\end{array}$ & CD-ROM & $\begin{array}{l}\text { Chagas/ } \\
\text { Dengue }\end{array}$ & $\begin{array}{l}\text { Profissionais de } \\
\text { Saúde }\end{array}$ & $\begin{array}{l}\text { Capacitação } \\
\text { Profissionais Saúde }\end{array}$ & $\begin{array}{l}\text { Princípios do } \\
\text { Ergodesign }\end{array}$ & $\begin{array}{l}\text { Autores do } \\
\text { Artigo }\end{array}$ \\
\hline $\begin{array}{l}\text { TORAL et al, } \\
2009\end{array}$ & Impresso & $\begin{array}{l}\text { Alimentação } \\
\text { Saudável }\end{array}$ & $\begin{array}{l}\text { Adolescentes } \\
\text { Alunos }\end{array}$ & Educação em Saúde & \begin{tabular}{l|} 
Características \\
Necessárias \\
\end{tabular} & Adolescentes \\
\hline $\begin{array}{l}\text { KELLY- } \\
\text { SANTOS et al, } \\
2009\end{array}$ & $\begin{array}{l}\text { Cartazes e } \\
\text { Cartilhas }\end{array}$ & Hanseníase & $\begin{array}{l}\text { Profissionais de } \\
\text { Saúde Pacientes }\end{array}$ & Educação em Saúde & Recepção & $\begin{array}{l}\text { Profissionais de } \\
\text { Saúde }\end{array}$ \\
\hline $\begin{array}{l}\text { MANO et al, } \\
2009\end{array}$ & Multimidia & Sexualidade & Jovens & $\begin{array}{l}\text { Espaços Ed.Formais/ } \\
\text { Não Formais }\end{array}$ & $\begin{array}{l}\text { Avaliações } \\
\text { e Sugestões } \\
\text { diversas }\end{array}$ & $\begin{array}{l}\text { Jovens do } \\
\text { Ensino Médio }\end{array}$ \\
\hline $\begin{array}{l}\text { KELLY- } \\
\text { SANTOS et al, } \\
2010\end{array}$ & $\begin{array}{l}\text { Acervo de } \\
\text { Materiais }\end{array}$ & Hanseníase & Público em Geral & $\begin{array}{l}\text { Educ. em Saúde / } \\
\text { Campanhas }\end{array}$ & $\begin{array}{l}\text { Tipo, Público, } \\
\text { Objetivos e } \\
\text { Uso }\end{array}$ & $\begin{array}{l}\text { Autores do } \\
\text { Artigo }\end{array}$ \\
\hline $\begin{array}{l}\text { SANTOS et al, } \\
2012\end{array}$ & $\begin{array}{l}\text { Educativos } \\
\text { Impressos }\end{array}$ & Hanseníase & $\begin{array}{l}\text { População e } \\
\text { Pacientes }\end{array}$ & $\begin{array}{l}\text { Educ. em Saúde } \\
\text { Campanhas }\end{array}$ & ecepção & $\begin{array}{l}\text { Prof. Saúde e } \\
\text { Pacientes }\end{array}$ \\
\hline $\begin{array}{l}\text { ROSSI et al, } \\
2012\end{array}$ & Cartazes & \begin{tabular}{|l|} 
Parasitoses \\
Intestinais \\
\end{tabular} & $\begin{array}{l}\text { Crianças Escolares } \\
7 \text { a } 11 \text { anos }\end{array}$ & Educação em Saúde & $\begin{array}{l}\text { Potenciais } \\
\text { Deficiências }\end{array}$ & $\begin{array}{l}\text { Autores (artigo } \\
\text { e material) }\end{array}$ \\
\hline $\begin{array}{l}\text { SOUZA e } \\
\text { OLIVEIRA, } \\
2013\end{array}$ & $\begin{array}{l}\text { Material } \\
\text { Curricular } \\
\text { (escola) }\end{array}$ & $\begin{array}{l}\text { Literatura } \\
\text { Infantil e } \\
\text { Matemática }\end{array}$ & $\begin{array}{l}\text { Crianças Início } \\
\text { Ens. Fundamental }\end{array}$ & Escolar & $\begin{array}{l}\text { Elaboração do } \\
\text { Material e Uso }\end{array}$ & $\begin{array}{l}\text { Autores (artigo } \\
\text { e material) }\end{array}$ \\
\hline $\begin{array}{l}\text { KAWAMOTO e } \\
\text { CAMPOS, } 2014\end{array}$ & $\begin{array}{l}\text { História em } \\
\text { Quadrinhos }\end{array}$ & Corpo humano & $\begin{array}{l}\text { Crianças Ens. } \\
\text { Fund. }\end{array}$ & Escolar & $\begin{array}{l}\text { Elaboração e } \\
\text { Avaliação }\end{array}$ & Alunos 5o. ano \\
\hline $\begin{array}{l}\text { VIEIRA e } \\
\text { GOMES, } 2014\end{array}$ & Livro Didático & Matemática & $\begin{array}{l}\text { Anos Iniciais Ens. } \\
\text { Fund. }\end{array}$ & Escolar & Uso & Professores \\
\hline $\begin{array}{l}\text { MONTEIRO e } \\
\text { BIZZO, } 2014\end{array}$ & Livro Didático & Saúde & $\begin{array}{l}\text { Anos Iniciais Ens. } \\
\text { Fund. }\end{array}$ & Escolar & $\begin{array}{l}\text { Conteúdo } \\
\text { Saúde-Doença }\end{array}$ & Autores Artigo \\
\hline $\begin{array}{l}\text { MATOS e } \\
\text { STELKO- } \\
\text { PEREIRA, } 2015\end{array}$ & Folder & $\begin{array}{l}\text { Abuso Sexual } \\
\text { Infantil }\end{array}$ & Universitários & Universidade & $\begin{array}{l}\text { Análise } \\
\text { Aparente }\end{array}$ & $\begin{array}{l}\text { Especialistas, } \\
\text { Universitários } \\
\text { Vítimas }\end{array}$ \\
\hline $\begin{array}{l}\text { SOUZA et al, } \\
2015\end{array}$ & Impresso & \begin{tabular}{|l|} 
Direitos \\
Sexuais e \\
Reprodutivos
\end{tabular} & $\begin{array}{l}\text { Enfermeiros } \\
\text { Usuários }\end{array}$ & Educação em Saúde & $\begin{array}{l}\text { Influência e } \\
\text { Uso }\end{array}$ & $\begin{array}{l}\text { Autores Artigo, } \\
\text { Enfermeiros } \\
\text { Usuários }\end{array}$ \\
\hline $\begin{array}{l}\text { SOBRINHO- } \\
\text { SANTOS et al, } \\
2015\end{array}$ & Impresso & $\begin{array}{l}\text { AIDS e } \\
\text { Prevenção } \\
\text { HIV }\end{array}$ & Caminhoneiros & Educação em Saúde & $\begin{array}{l}\text { Potencial } \\
\text { Educativo }\end{array}$ & Caminhoneiros \\
\hline
\end{tabular}


Como parte dos procedimentos metodológicos acima descritos, a leitura das fichas catalográficas foi retomada com o objetivo de agrupar os artigos de modo a ser possível montar um quadro visual da literatura de pesquisa sobre o nosso tema a partir do referencial adotado (CRESWELL, 2007). O resultado deste procedimento está representado pelo Quadro1, onde os 19 artigos foram dispostos pelos nomes dos Autores e em ordem cronológica, sendo nas demais colunas apresentadas as características dos artigos que melhor contemplam as questões de interesse para a pesquisa já apontadas anteriormente e apresentados à seguir.

\section{1 Tipos de Materiais}

Os materiais analisados apresentaram variados suportes, como CD ROM, folhetos, folder, cartilhas, cartazes, textos, impressos em geral, materiais curriculares, histórias em quadrinhos, livros e livros didáticos. Percebeu-se a predominância dos impressos.

Freitas e Cabral (2008) consideram que o material impresso, para pacientes e familiares no caso específico da traqueostomia, facilita o processo educativo, permitindo uma leitura posterior à consulta, reforçando assim as informações orais. Provavelmente este processo educativo pode se estender a outros campos e tomar proporções inesperadas, conforme citação abaixo:

Impressos são materiais com pernas longas e muito fôlego: correm mundos, muito além da circulação planejada e controlada, são replicados, desdobrados, convertidos em textos de rádio, vídeos e televisão. Por isto, deve-se cuidar para que seu conteúdo possa dispensar a presença de mediadores. (ARAÚJO, 2006, p. 67).

\section{2 Área Temática}

A temática abordada pelos materiais analisados neste estudo também mostra-se variada, porém a grande maioria apresenta-se localizada no campo da saúde, sendo apenas um artigo relacionado à Matemática e outro à Literatura Infantil e Matemática. Os artigos produzidos no campo da saúde se delimitaram à: Hanseníase (3), Leishmaniose (2), Alimentação Saudável (2), Saúde do Trabalhador (1), Traqueostomia (1), Doença de Chagas e Dengue (1), Sexualidade (1), Parasitose Intestinal (1), Corpo Humano (1), Saúde (1) Abuso Sexual Infantil (1), Direitos Sexuais e Reprodutivos (1), AIDS e Prevenção HIV (1). Cabe esclarecer que muitos destes artigos analisaram acervos de materiais, materiais coletados ou coleções didáticas, sendo que estas últimas fogem ao escopo deste estudo (LUZ et al, 2003, CASTRO et al, 2007, PIMENTA et al, 2008, KELLY-SANTOS et al, 2009, KELLY-SANTOS et al, 2010, ROSSI, et al 2012, SANTOS et al, 2012, SOUZA; OLIVEIRA, 2013, MONTEIRO; BIZZO, 2014). Excetuando-se os artigos que se referiram à alimentação saudável, não houve menção de materiais relacionados à promoção da saúde.

\section{3 Público}

Os destinatários dos materiais nos artigos analisados (Quadro 1) foram: Escolares (8), principalmente do ensino fundamental, sendo adolescentes (2), crianças ou alunos dos anos iniciais do ensino fundamental (5), e jovens do ensino médio (1); pacientes relacionados a doenças específicas (4); trabalhadores (6), em geral, da educação e da saúde, Público em Geral e caminhoneiros (1), Usuários do SUS (1) e Universitários (1). Destacamos que em cinco dos 19 artigos, o público para quem o material se destinava era mais de um grupo.

\section{4 Locais/Formas de Uso}

Sobre o contexto de uso, os materiais estiveram relacionados às atividades de: Educação em Saúde / Serviços de Saúde / campanhas (11); uso escolar / universidade (6), sendo com propósito pedagógico e curricular 
(4), espaços de educação formal/não formal (1); capacitação de profissionais de saúde (1) e distribuição de impressos a trabalhadores (1). A Educação em Saúde caracteriza-se pela associação de atividades educativas, além da distribuição dos materiais como consulta, orientação ou ações complementares ao uso do material de forma integrada; estas atividades aconteceram nos serviços de saúde e na escola (CASTRO, 2007). Sobre a distribuição, ocorre em locais de trabalho, sindicatos, secretarias, seja por mala direta ou entregue durante as inspeções, sem relato de ação educativa (KELLY-SANTOS; ROZEMBERG, 2005). As autoras comentam sobre os produtores destes materiais, que a preocupação "distributivista” e a tendência ao público abrangente pressupõe que a divulgação dos conhecimentos possibilite adesão dos usuários aos programas, atingindo assim o maior número de pessoas.

\section{5 Aspectos Metodológicos da Análise}

As análises/avaliações descritas nos artigos selecionados foram diversificadas quanto ao tipo, sendo assim sumarizadas: Avaliações Gerais (7) - Opinião, Características Necessárias (expectativas), Avaliações, Sugestões Diversas, Potenciais Deficiências e Influências; Específicas (4) - Análise Sintática, Lógica e Linguagem, Princípios do Ergodesign, Conteúdo Saúde-Doença, Análise Aparente; Caracterização do Material (5) - Tipo, Público, Objetivos, Aplicação, Uso; Recepção e Processos Comunicativos (3); Elaboração (2); Informações (3) - Qualidade, Potencial (conhecimento após leitura) e potencial Educativo. As metodologias em sua grande maioria possuem abordagem qualitativa, dentre elas citamos: análise documental, estudo de caso, história oral, entrevistas até os grupos focais.

Quanto ao tipo de análise/avaliações denominada 'específicas', consideramos importante apresentar suas descrições. No quadro 1, as Análises Sintática, Lógica e Linguagem foram citadas para exemplificar o que as autoras fizeram. Freitas e Cabral (2008), destacaram os recursos de comunicação expressos e os conteúdos textuais veiculados no folheto educativo que analisaram. Deste modo, foi possível verificar qual conteúdo o material expressa; revelar as diferentes linguagens empregadas - ambígua, popular; analisar a lógica do texto, bem como as condições de produção da palavra, evidenciando as posições do locutor e leitor.

As análises realizadas visando avaliar os princípios do ergodesign (PIMENTA et al, 2008), valorizaram a usabilidade do material educativo. Estes princípios compreendem o conjunto de fatores que asseguram que os produtos sejam fáceis de usar, eficientes e agradáveis da perspectiva do usuário, além de proporcionar um ambiente dinâmico e interativo para a construção de conhecimento. A avaliação dos materiais foi realizada com o ergolist, uma ferramenta baseada nos critérios de concisão, mensagens de erro, flexibilidade, legibilidade, significados, proteção contra erros, agrupamento por formato, experiência do usuário, presteza, controle do usuário, correção de erros, consistência, agrupamento por localização, densidade informacional, feedback, compatibilidade, ações explícitas e ações mínimas.

A Análise Aparente (MATOS; STELKO-PEREIRA, 2015) pretende investigar as instruções do material quanto à facilidade de leitura e entendimento, quanto à possibilidade de causar constrangimento em seu leitor e se é fidedigno à literatura científica apontada (PASQUALI, 1997). Como instrumento para coleta dos dados, as autoras utilizaram uma versão adaptada do EVALPEM-Evaluation of Printed Education Materials, isto é, avaliação de materiais educativos impressos (CASTRO, 2007).

\section{6 Sujeitos da Análise}

Denominamos Sujeitos da Análise os indivíduos que atuaram nas análises nos materiais. Foram: Autores do artigo (8), sendo 2 deles os produtores do material; Público (9) - alunos do $5^{\circ}$ ano, jovens do ensino médio, adolescentes, universitários, pacientes, usuários do SUS, caminhoneiros e leigos; Público Intermediário ou Usuário do material (6) - profissionais da saúde ou da educação usam o material como instrumento de trabalho com o público alvo; Especialistas (2) - profissionais especializados na temática abordada no material ou da área de informação, adultos universitários ou formados. Nota-se a crescente preocupação dos autores dos artigos 
em avaliar os materiais, embora a análise tenha sido realizada em sua maioria pelos próprios, e também destaca-se a análise protagonizada pelo próprio público ao qual se destina. Em 2005, foram iniciados os relatos que identificavam as visões dos pacientes, alunos ou profissionais que usam estes materiais, não só com o intuito de melhorá-los, mas de compreender as relações entre os sujeitos e os seus usos. Rossi et al (2012), apontam o fato de serem os sujeitos produtores, eles mesmos, avaliadores do material e autores do artigo, possibilitando, após alguns anos da criação, mediante o aprofundamento no estudo sobre produção de materiais, a identificação de falhas, inclusive metodológicas e conceituais. Os autores ressaltam a importância da crítica proporcionada por esta reflexão para o desenvolvimento de materiais de apoio a projetos de ensino-pesquisa-extensão na universidade.

\section{CONSIDERAÇÕES FINAIS}

A análise conjunta dos artigos levantados aponta diferentes aspectos relacionados à produção, público, uso e avaliação de materiais. Convergindo com os pressupostos deste estudo, percebe-se predominarem recomendações acerca da produção destes materiais que incorpore os atores como sujeito de conhecimento, não apenas como público-alvo de produtos construídos fora de suas realidades. Ou seja, de acordo com os artigos analisados os materiais necessitam ser produzidos a partir das necessidades do público-usuário das ações educativas, levando-se sempre em conta o contexto e a finalidade de uso (FREITAS; CABRAL, 2008; PIMENTA et al, 2008; LUZ et al, 2003; KELLY-SANTOS et al, 2009; TORAL et al, 2009; SOUZA et al, 2015). No entanto, permanece um desafio o envolvimento dos sujeitos no processo de produção de materiais e seus usos, bem como a relação dos especialistas com seu público. Como apontaram os dados deste estudo, a produção indica que a ênfase na avaliação recai nos profissionais e especialistas dedicados ao tema, numericamente superior nos artigos levantados, embora se observe existir algum protagonismo pelo próprio público para o qual se destinam as ações.

De acordo com a literatura do campo, no contexto da saúde, a inserção do público no desenvolvimento do material propicia o pensamento reflexivo e a discussão sobre a saúde como um processo (KELLY-SANTOS; ROZEMBERG, 2005). Para tanto, o conhecimento da situação epidemiológica da doença, em se tratando dos agravos à saúde, pode auxiliar na definição deste público, o que permite planejar e realizar estratégias comunicativas mais efetivas (KELLY-SANTOS et al, 2010). Mas este procedimento não esgota a identificação de quem são estas pessoas e/ou grupos sociais susceptíveis e como eles vivem, se considerarmos o potencial dos materiais nesta aproximação com a realidade social. No entanto, pesquisas sobre avaliação dos materiais demonstram forte tendência de os profissionais de saúde usarem os materiais de forma instrumental. Para as autoras Kelly-Santos et al, 2010, este enfoque está em consonância com ações educativas verticais, unilaterais e lineares, caracterizadas pela fragmentação dos processos comunicativos, privilegiando o saber do técnico e excluindo o destinatário das etapas de produção (LUZ et al, 2003; KELLY- SANTOS et al, 2009).

Tendo em vista esta crítica presente na literatura do campo, assumimos a perspectiva teórica de González Rey (2003), que nos ajuda a analisar como a ausência da categoria sujeito, ou a sua pouco expressividade neste campo como categoria de análise, pode expressar uma tendência autoritária e domesticadora das instituições que não toleram manifestações personalizadas e, com isto, impedindo que o indivíduo visualize práticas que facilitem seu desenvolvimento. Dessa forma, compreendemos que a categoria sujeito implica, no contexto das práticas e intervenções educativas, em participação do indivíduo que, por sua vez, está arraigada à prática social.

Em contraponto à prática instrumental hierarquizada identificada, os artigos analisados e dedicados à análise dos materiais cuja produção foi colaborativa e/ou envolveu avaliação dos seus produtos e momentos permeados pela discussão coletiva, demonstraram benefícios tanto para os participantes da elaboração quanto para o público, extrapolando sua utilização imediata e contribuindo fortemente para o desenvolvimento e crescimento da equipe envolvida, inclusive em ambientes formativos (KELLY-SANTOS et al, 2009; ROSSI et al, 2012; SOUZA; OLIVEIRA, 2013). Adicionalmente, as autoras Souza et al (2015) destacam a relevância da produção de materiais informativos próprios como alternativa eficaz na sua potencialização como ferramentas de promoção da saúde, em virtude de possuírem linguagem e abordagem compatíveis com as especificidades do 
público-alvo (FREITAS; CABRAL, 2008), embora esta prática tenha sido uma exceção dentre os profissionais do estudo.

Tendo em vistas estes resultados, consideramos importante implementar, em diferentes espaços formativos no ensino em ciências, atividades que favoreçam o diálogo, a análise/avaliação e o trabalho colaborativo (SOUZA; OLIVEIRA, 2013), bem como no campo da saúde, e incluir estas etapas no planejamento, seja das ações de controle dos programas ou no desenvolvimento dos materiais (FREITAS; CABRAL, 2008; PIMENTA et al, 2008; KELLY-SANTOS et al, 2010; SANTOS et al, 2012; MATOS; STELKO-PEREIRA, 2015).

\section{REFERÊNCIAS}

ARAÚJO, I. Materiais educativos e produção de sentidos na intervenção social. In: Monteiro, S.S., Vargas, E.P. (Orgs.). Educação, Comunicação e Tecnologia Educacional: interfaces com o campo da saúde. 1ed. Rio de Janeiro: Editora Fiocruz, 2006. 49-70 p.

BRITO, I. F. A Psicologia do Desenvolvimento. In: Desenvolvimento Infantil: Concepções de Professores e suas implicações na manifestação do preconceito. Dissertação (Mestrado em Educação) - Faculdade de Educação, Universidade de Brasília, Brasília, 2005. 1-24 p. Disponível em: <https://googlegroups.com/group/ aprendizagem-e-desenvolvimento_pos/attach/aa01a077254e725e/Ildamar_dissertação.doc?part=0.3>. Acesso em: 10 out. 2016.

CASTRO, I. R. R. S.; et al. A culinária na promoção da alimentação saudável: delineamento e experimentação de método educativo dirigido a adolescentes e a profissionais das redes de saúde e de educação. Rev. Nutr. Campinas, v. 20, n. 6, dez. 2007. 571-588 p.

CASTRO, M. S.; PILGER. F. D.; FERREIRA, M. B. C. Development and validity of a method for the evaluation of printed education material. Pharm Prac. New York, v.5, 2007. 89-94p.

COORDENADORIA DE COOPERAÇÃO SOCIAL DA PRESIDÊNCIA(CCSP)/FIOCRUZ. Experiências do Edital de Cooperação Social para o Desenvolvimento Territorializado 02/2011. Rio de Janeiro, 2014. 38 p.

CRESWELL, J. W. Projeto de pesquisa: métodos qualitativo, quantitativo e misto. Porto Alegre: Artmed, 2007. 43-63 p.

DIB, S. F.; SILVA, N.C. (Orgs.). Roteiro para apresentação das teses e dissertações da Universidade do Estado do Rio de Janeiro. 2 ed. Rio de Janeiro: UERJ, Rede Sirius, 2012

FERREIRA, N. S. A. As pesquisas denominadas “estados da arte”. Educação e Sociedade, Campinas, v. 23, n.79, 2002. 257-272 p.

FIELD, H.; POWELL, P. Public understanding of science versus public understanding of research. Public Understand. Science, United Kingdom, v. 10,. 2001. 421-426 p.

FREITAS, F. V.; REZENDE FILHO, L. A. Modelos de comunicação e uso de impressos na educação em saúde: uma pesquisa bibliográfica. Interface, Botucatu,. v. 15, n. 36, 2011. 243-256 p.

FREITAS, A. A. S.; CABRAL, I. E. O cuidado à pessoa traqueostomizada: análise de um folheto educativo. Esc. Anna Nery, Rio de Janeiro, v. 12, n. 1, 2008. 84-89 p.

GONZÁLEZ-REY, F. Sujeito e subjetividade. São Paulo: Thomson, 2005. 290 p. 
KAPLÚN, G. Material Educativo: a experiência do aprendizado. Comunicação e Educação, São Paulo, v. 27, maio/ago, 2003. 46-60 p.

KAWAMOTO, E. M.; CAMPOS, L. M. L. Histórias em quadrinhos como recurso didático para o ensino do corpo humano em anos iniciais do Ensino Fundamental. Ciênc. Educ., Bauru, v. 20, n. 1, 2014. 147-158 p.

KELLY-SANTOS, A.; ROZEMBERG, B. Comunicação por impressos na saúde do trabalhador: a perspectiva das instâncias públicas. Ciênc. saúde coletiva, Rio de Janeiro, v. 10, n. 4, 2005. 929-938 p.

KELLY-SANTOS, A.; MONTEIRO, S.; ROZEMBERG, B. Significados e usos de materiais educativos sobre hanseníase segundo profissionais de saúde pública do Município do Rio de Janeiro, Brasil. Cad. Saúde Pública, Rio de Janeiro, v. 25, n. 4, 2009. 857-867 p.

KELLY-SANTOS, A.; MONTEIRO, S. S.; RIBEIRO, A. P. G. Acervo de materiais educativos sobre hanseníase: um dispositivo da memória e das práticas comunicativas. Interface, Botucatu, v. 14, n. 32, 2010. 37-51 p.

LUZ, Z. M. P. Evaluation of informative materials on leishmaniasis distributed in Brazil: criteria and basis for the production and improvement of health education materials. Cad. Saúde Pública, Rio de Janeiro, v. 19, n. 2, 2003. 561-569 p.

LUZ, Z. M. P.; SCHALL, V.; RABELLO, A. Evaluation of a pamphlet on visceral leishmaniasis as a tool for providing disease information to healthcare professionals and laypersons. Cad. Saúde Pública, Rio de Janeiro, v. 21, n. 2, 2005. 608-621 p.

MANO, S. M. F.; GOUVEIA, F. C. e SCHALL, V. T. “Amor e sexo: mitos, verdades e fantasias”: jovens avaliam potencial de material multimídia educativo em saúde. Ciênc. Educ., Bauru,. v. 15, n. 3, 2009. 647-658 p.

MATOS, K. J. N.; STELKO-PEREIRA, A. C. Análise Aparente de Tecnologia Educativa para Universitários sobre Abuso Sexual Infantil. Psico-USF, Itatiba, v. 20, n. 2, ago. 2015. 349-352 p.

MONTEIRO, P. H. N.; BIZZO, N. Hábitos, atitudes e ameaças: a saúde nos livros didáticos brasileiros. Cad. Pesqui., São Paulo, v. 44, n. 151, 2014. 132-154 p.

MONTEIRO, S. S.; VARGAS, E. P. (Orgs.). Educação, Comunicação e Tecnologia Educacional: interfaces com o campo da saúde. 1ed. Rio de Janeiro: Editora Fiocruz, 2006. 252p.

MONTEIRO, S. S.; VARGAS, E. P.; CRUZ, M. Desenvolvimento e uso de tecnologias educacionais no contexto da Aids e da saúde reprodutiva: reflexões e perspectivas. In: Monteiro, S.S., Vargas, E.P. (Orgs.) Educação, Comunicação e Tecnologia Educacional: interfaces com o campo da saúde. 1ed. Rio de Janeiro: Editora Fiocruz, 2006. 27-48 p.

NOGUEIRA, M.; MODENA, C.; SCHALL, V. Materiais educativos impressos sobre saúde sexual e reprodutiva utilizados na atenção básica em Belo Horizonte, MG: caracterização e algumas considerações. RECIIS, Rio de Janeiro, v. 3, 2009. 169-179 p.

PASQUALI, L. Psicometria: Teoria e aplicações. 1 ed. Brasília: Editora Universidade de Brasília, 1997.

PIMENTA, D.N.; SILVA LEANDRO, A.M.; SHALL, V. Experiências de desenvolvimento e avaliação de materiais educativos sobre saúde: abordagens sócio-históricas e contribuições da antropologia visual. In: Monteiro, S.S., Vargas, E.P. (Orgs.). Educação, Comunicação e Tecnologia Educacional: interfaces com o campo da saúde. 1 ed. Rio de Janeiro: Editora Fiocruz, 2006. 87-112 p. 
PIMENTA, D.N.; DINIZ, H. M. N.; ANDRADE, M. A. M.; OLIVEIRA, P. R.; SILVA, J. F.; DIAS, J. C. P.; SCHALL, V. T.; SANTOS, R. A importância do ergodesign na avaliação de cd-rom sobre dengue e doença de chagas na educação em saúde. Trab. Educ. Saúde. Rio de Janeiro, v. 6, n. 1, 2008. 147-167 p.

ROSSI, S. Q. et al. Um novo olhar sobre a elaboração de materiais didáticos para educação em saúde. Trab. Educ. Saúde, Rio de Janeiro, v. 10, n. 1, 2012. 161-176 p.

SANTOS, A. K.; RIBEIRO, A. P. G.; MONTEIRO, S. Hanseníase e práticas da comunicação: estudo de recepção de materiais educativos em um serviço de saúde no Rio de Janeiro. Interface, Botucatu, v. 16, n. 40, 2012. 205218 p.

SOBRINHO-SANTOS, C. K. et al. Relatos de caminhoneiros sobre a prevenção do HIV e o material educacional impresso: reflexões para educação em saúde. Ciênc. Educ., Bauru, v. 21, n. 4, 2015. 1011-1030 p.

SOUZA, A. P. G.; OLIVEIRA, R. M. M. A. Aprendizagem da docência em grupo colaborativo: histórias infantis e matemática. Educ. Pesqui., São Paulo, v. 39, n. 4, 2013. 859-874 p.

SOUZA, L. M.; MORAIS, R. L. G. L.; OLIVEIRA, J. S. Direitos sexuais e reprodutivos: influências dos materiais educativos impressos no processo de educação em sexualidade. Saúde debate, Rio de Janeiro, v. 39, n. 106, set. 2015. 683-693 p.

TORAL, N.; CONTI, M. A.; SLATER, B. A alimentação saudável na ótica dos adolescentes: percepções e barreiras à sua implementação e características esperadas em materiais educativos. Cad. Saúde Pública, Rio de Janeiro, v. 25, n. 11, 2009. 2386-2394 p.

VARGAS, E.P.; MONTEIRO, S.S. Banco de Materiais: Desenvolvimento e estímulo a novas pesquisas. In: MONTEIRO, S. S.; VARGAS, E. P. (Orgs.). Educação, Comunicação e Tecnologia Educacional: interfaces com o campo da saúde. 1ed. Rio de Janeiro: Editora Fiocruz, 2006. 143-154 p.

VIEIRA, G. M.; GOMES, M. L. M. Livros didáticos e formação de professores que ensinam Matemática nos anos iniciais do Ensino Fundamental. Educ. Rev., Marília, n. 54, 2014. 257-274 p.

ZANON, D. A. V.; GUERREIRO, M. A. S.; OLIVEIRA, R. C. Jogo didático Ludo Químico para o ensino de nomenclatura dos compostos orgânicos: projeto, produção, aplicação e avaliação. Cien. Cogn., Rio de Janeiro, v. 13, n. 1, 2008. 72-81 p. 